\title{
The Effect of Repeated Reading on the Pronunciation of Young EFL Learners
}

\author{
IRENE Riquelme GiL \\ Julio Roca de LaRios \\ Yvette Coyle Balibrea \\ Universidad de Murcia
}

Received: 15 November 2015 / Accepted: 25 February 2016

ISSN: 1697-7467

\begin{abstract}
This study explores whether the Repeated Reading (RR) method can help young Spanish EFL learners improve their pronunciation. The study was carried out with eight 10-to-11year old children who systematically read different passages from the same storybook for six weeks. Data were collected in a pretest and three post-tests involving the re-reading of the original text, reading of an unknown textand an oral interview. Data were analyzed with a classification of pronunciation error types focusing on vowels and consonants. The results indicated that the children improved their pronunciation on the three posttests, especially when producing free speech.
\end{abstract}

Keywords: Repeated Reading (RR), pronunciation, young learners, foreign language learning.

Influencia del método "lectura repetida" en la pronunciación de jóvenes aprendices de inglés.

RESUMEN: Este estudio pretende analizar si el método de Lectura Repetitiva (Repeated Reading) mejorala pronunciación de niños de Educación Primaria. Sepracticó con ocho niños de quinto curso queleyeronsistemáticamente distintos pasajesdel mismo libro durante seis semanas. Los datos fueron recogidos con un pretesty tres post-tests, incluyendo una relectura del primer texto, lectura de un fragmento nuevo y entrevista oral.Los datos fueron analizados usando una clasificación de tipos de errores en pronunciación incluyendo vocales, consonantes y acentuación. Los resultados indicaron que los niños mejoraron su pronunciación en los tres post-tests, especialmente al producir lengua oral libremente.

Palabras claves: Lectura Repetitiva, pronunciación, niños de Primaria, enseñanza de lengua extranjera.

\section{Introduction}

Acceptable pronunciation is one of the key characteristics of a fluent speaker, since speech, which is grammatically accurate but full of pronunciation errors, is likely to be unintelligible for listeners. Comprehensibilityalso has an important influence on how L2 speakers are perceived outside the language classroom. Non-native speakers whose speech is not easily understood are sometimes perceived as less intelligent and less suitable for 
some occupations (Dlaska and Klekeler, 2008). Conversely, if speech comprehensibility is high thanks to accurate pronunciation, foreign speakers may have more opportunities for socialization with L2 speakers (Robertson, 2003) and their communicative competence is likely to improve (Fraser, 1999).

In consonance with these claims, and with the alleged benefits associated with the learning of pronunciation at an early age (see LázaroIbarrola, 2011; Kendrick, 1997), official curriculum guidelines recommend that pronunciation should be taught to children as early as possible. Within the area of English as a foreign language, one of the stated aims of the curriculum is that learners become aware of segmental and supra-segmental patterns of English so that they can be used as basic elements of communication. However, in spite of these recommendations, the teaching of pronunciation remains largely overlooked in most primary schools.

In an attempt to address this gap, the present study attempts to explore whether Repeated Reading (RR, henceforth), a pedagogical procedure based on reading texts aloud, is an adequate technique to help primary schoolchildren (i) develop and enhance their English pronunciation, and (ii) transfer their reading gains (if any) to their free speech production. In order to answer these questions, a 5-week intervention programme was conducted with a group of Spanish EFL learners aged 10 to 11, who were trained in reading selected texts from a graded storybook for primary readers.

\section{BaCKGROUND TO THE STUdY}

\subsection{Reading aloud as a pronunciation teaching technique}

As suggested by LázaroIbarrola(2011), EFL teaching methodology does not generally recommend reading aloud (but see Gibson, 2008, for exceptions) on the grounds that it is not focused on developing children's comprehension (Dwyer, 1983; Gabrielatos, 2002). In fact, learners can read aloud correctly without understanding what they are reading (Wallace, 1992).However, when reading aloud (RA, henceforth) is not used for the purpose of teaching comprehension but with the sole purpose of teaching pronunciation, as is the case in the present study, it may offer different advantages. RA is expected to help learners strengthen the grapho-phonemic correspondences of the L2 (Gibson, 2008), however complex its orthographic system may be (LázaroIbarrola, 2011). It is also thought to aid the acquisition of prosodic or supra-segmental dimensions of the language (rhythm and intonation), although these dimensions have been regarded by some authors as very difficult to teach (e.g., Macdonald, Yule and Powers, 1994; Yule and MacDonald, 1995). Finally, RA may be very motivating for students if the texts to be read are selected on the basis of the learners' own interests, and may also help them reduce their apprehension and feel more confident when speaking (LázaroIbarrola, 2011).

\subsection{The Repeated Reading method}

One of the most relevant methodological procedures used both in L1, and to a lesser extent in L2 contexts, to help learners develop their reading aloud skills is the so called Re- 
peated Reading (RR) method, which was originally proposed by Samuels (1979, in Taguchi, Takayasu and Gorsuch, 2004). According to this author, RR consists of re-reading a short passage both silently and aloud until the reader is able to do so with ease. An alternative definition was provided by Huey (1986, in Wang and Kuo, 2011), who considers RR as the practice of reading texts again and again until the learner can do so easily, effortlessly and fluently. Within RR, two varieties can be distinguished (Samuels, 1979; Bouguebs, 2005; Taguchi et al., 2004): (i) Assisted Repeated Reading or Repeated Oral Reading, whereby learners read different pieces of text out loud while being guided by the teacher or an audio-taped model; and (ii) Unassisted Repeating Reading or Independent Silent Reading, whereby learners read selected passages silently and independently, both inside or outside the classroom.

On the basis of this characterization of RR, most studies have explored whether RR is effective in enhancing learners' fluency when reading (e.g., Taguchi, Takayasu and Gorsuch, 2004; Wang and Kuo, 2011; Chen and Chang, 2008; Bouguebs, 2005). However, as articulation speed and accuracy, the two basic components of fluency, are also essential components of pronunciation, it is our contention that RR might also be used to improve L2 learners' pronunciation skills. Thus, the point of departure of the present study is that, in addition to its traditional use for reading fluency purposes, RR may also be used for pronunciation teaching purposes. These may include, for example, helping learners articulate consonants and vowels or use appropriate rhythm and stress.

One of the potential advantages of RR concerns the transfer of the pronunciation gains obtained from rereading familiar texts in class, to the reading of unknown texts. In this sense, several authors have reported the beneficial effects of accumulated reading practices on readers' rate, accuracy, comprehension and prosodic reading (Dowhower, 1987; Samuels, 1979; Blevins and Lynch, 2000; Invernizzi, 2002, in Bouguebs, 2005), provided that the number of overlapping words between the original and the new passages is high (Rashotte and Torgesen, 1985, in Taguchi, Takayasu and Gorsuch, 2004).

Other authors have suggested that the rereading of selected passages may also have a direct effect on learners' oral skills in terms of improved pronunciation (Chen, 2003 in Wang and Kuo, 2011). However,sincevery little research has been conducted on this issue, the influence of RR on the improvement of oral output production is still undetermined. Lázaro (2011) examined the effects of the imitation of oral texts on Spanish university students'pronunciationand found that the participants were unable to transfer the suprasegmental skills acquired from reading activities to their oral production. This was attributed to the fact that in the post-test the learners were required to talk about a free topic whose word overlap with the activities implemented in class was almost non-existent.

In contrast with the attention paid to RR in L1 contexts, this method has scarcely been used in second language or EFL contexts. The few scholars who have attempted to discover the effects of RR on learning English as an L2examined RR with i) Japanese EFL university students (Taguchi, Takayasu and Gorsuch, 2004), ii) Taiwanese EFL college students (Wang and Kuo, 2011) and high school students (Chen and Chang, 2008), andiii) Algerian university students (Bouguebs, 2005). The results of these studies have shown that, with older learners at least, RR can lead to a general increase in oral reading speed, since it was shown that the steady repetitions of the same text enabled the students to read more words per minute and more accurately; enhancing their predisposition to read long fragments of 
text and in developing their capacity to cope with new words. RR was also found to improve word recognition skills as well as comprehension abilities, giving learners the possibility of transferring these gains to new unpracticed passages.

\subsection{Limitations of current research}

In spite of the insights offered, the studies reviewed above share a number of characteristics in relation to the type of populations analyzed and the methodological procedures employed that, collectively considered, suggest a number of issues which need to be explored in further research.Firstly, the participants included in the studies are university students (Taguchi, Takayasu and Gorsuch, 2004; Wang and Kuo, 2011; Bouguebs, 2005; LázaroIbarrola, 2011) and EFL junior high school students (Chen and Chang, 2008), which means that the effects of RR on primary school children have been overlooked from an empirical perspective. Besides, while only one of those studies was carried out with learners whose mother tongue was Spanish (Lázaro, 2011), the others included participants with L1s such as Japanese (Taguchi, Takayasu and Gorsuch, 2004), Chinese (Wang and Kuo, 2011; Cheng and Chang, 2008) and Algerian (Bouygues, 2005). Hence, it may be concluded that the potential influence of the RR method on the L2 reading performance of Spanish schoolchildren still remains an open question. Secondly, and most importantly, the aim of the studies reviewed was to raise students' reading rates and fluency in general, with very little attention being paid to how accurately they read, pronounced and blended the words in the reading passages. This issue, however, is precisely what the present study intends to explore by examining the effect of RR on segmental aspects (vowels and consonants) of English pronunciation. It is beyond the aims of this proposal to use the method to teach supra-segmental features (word stress, rhythm and intonation) or reading for comprehension purposes.

The present study is an attempt to measure the effectiveness of the RR method on the pronunciation of eightyoungEFL primary school learners. On the basis of the literature reviewed above, it was assumed that the RR method would have a positive effect on the children's pronunciation skills. Another issue addressed in the study concerned whether any potential improvements would remain limited to the texts the children read in class or whether they could be transferred to the reading of new texts and to spontaneous speech. Consequently, the following research questions were formulated:

(i) Can young EFL learners improve thepronunciationof English vowels and consonants through the RR method?

(ii) Can children transfer any improvements made to (a) new texts, and (b) their production of free speech?

\section{Method}

\subsection{The participants}

The eight participants in the study (4 males and 4 females) were selected from a5th grade class of 17 Spanish EFL learners aged 10-year-old, who had been learning English at school from the age of three. Following the class teacher's recommendations, the children 
were selected on the grounds that (i) they had not experienced any EFL lessons outside school, which meant that their exposure to the foreign language was limited to three onehour lessons per week; (ii) they were generally positive and enthusiastic about the learning of English; and (iii) they includedthree different levels of L2 proficiency, which reflected the diversity of the children's language competence, as reflected in their performance in classroom activities. All the children in the class had previously received some limited phonetic instruction through the multi-sensory teaching method "Jolly Phonics" (Lloyd and Wernham, 1994) during the pre-school years. This enabled them to be familiar with some basicEnglish sounds at the time of data collection, such as $/ \mathrm{b} /, / \mathrm{v} /$ or $/ \mathrm{J} /$.

\subsection{The Study}

The study followed a pre-test post-test experimental design,whichwas conducted over a period of five weeks (see Table 1) by the principal researcher.Beforecommencing the study, the children's parents were informed of its main objectives and procedures, and were asked to sign a consent form to ensure their collaboration. In the initial session, the children were asked to read aloud a selected passage from a picture storybook (see Table 1 below) as an initial pre-test. Six 45-minute training sessions ( 2 per week) were then held to familiarize the learners with RR techniques.After each training session, the children took home the passage they had read with the researcher and were required to read it several times for practice purposes. The parents signed a reading card each time their children read one of the target passages. Once the training period was over, the children were given three post-tests, which included the re-reading of the pre-test passage, the reading aloud of a new passage and a brief interview intended to prompt them to speak about the story book.

\subsection{Teaching procedures}

The teaching procedures used to implement the RR method were as follows. All six sessions were held in a quiet room away from the main classroom and followed the same task sequence. The first part of each sessionfocused on assisted RR and began with a 5-minute task in which the recorded version of the selected passage was played while the group listened to it and read the printed version in silence. Fifteen minutes were then spent on reviewing the most difficult words and sentences in each passagethroughrepetition drills, so that the children could gradually become familiar with the pronunciation. The audio recording was then played three times more while the learners simultaneously attempted to read the passage aloud. The second part of the session focused on unassisted RR techniques. The group was now asked to read the passage aloud five times without the audio recording, paying attention to the pronunciation of the most difficult words. Finally, each individual child was audio recorded while reading aloud the selected passage. These recordings were kept for future analysis. 
Table 1.Temporal distribution of the study.

\begin{tabular}{|c|c|l|}
\hline Week & Session & \multicolumn{1}{|c|}{ Procedure } \\
\hline 1 & Pre-test & Pre -test of the reading passage \\
\hline $2-4$ & $2-6$ & $\begin{array}{l}\text { Assisted RR: } \\
\text { Individual silent reading of the selected passage with the audio record- } \\
\text { ing. } \\
\text { Repetition drills to practice difficult words } \\
\text { Individual reading aloud while listening to the audio recording (three } \\
\text { times) } \\
\text { Unassisted RR: } \\
\text { Individual reading aloud of the passage without listening to the audio } \\
\text { recording (five times) } \\
\text { Recording of each student's reading }\end{array}$ \\
\hline 5 & Post-test & $\begin{array}{l}\text { Post-test 1: Reading of the pre-test passage. } \\
\text { Post-test 2: Reading of a new passage from the same book. } \\
\text { Post-test 3: Responding to questions about the story plot. } \\
\text { Completion of questionnaire on the method. }\end{array}$ \\
\hline
\end{tabular}

\subsection{Materials used in the study}

The reading materials for the pre-test, the training sessions and the post-test consisted of eight passages extracted from the graded reader 'The Christmas Mouse' (Superfine, 2009), an elementary level storybook. The selected passages for each stage of the study (pre-test, training sessions and post-test) were all different. The book included a CD (a native-speaker reading the story aloud), which was also used in the training sessions. (seeTable 1). According to the teacher, who personally read the passages to be used on the project, most of the vocabulary used in the book was well known by the children in the group, thus the word overlap (Rashotte and Torgesen, 1985, in Taguchi, Takayasu and Gorsuch, 2004) between the different passages was high enough to allow for the potential transfer of pronunciation gains.

\subsection{Data collection instruments}

Data was collected for the study using the following instruments: (i) the pre-test reading passage; (ii) six reading passages for the training sessions; (iii)three post tests including the original pre-test passage, which was used again with the aim of identifying whether or not the children hadmade improvements from their initial performance; an unknown passage from the same book, which was especially selected to explore whether the children would be able to transfer any gains in pronunciation to unknown texts; and an oral interview 
about the story to check whether improvements in pronunciation were also manifested in the children's oral production.

The passages for the pre and posttests were specifically selected for a number of reasons (see Table 2). Firstly, both texts included what are generally considered to be words with troublesome soundsfor Spanish speakers (Monroy, 2001), such as the differences between /s/ and /z/ in "mouse" and "lives"; /b/ and /v/ in "big" and "clever"; and the pronunciation of sounds like /p/ in "pile", /dz/ in "ginger" /b/ in "big or "bottom", /k/ in "cat" or "cold", /h/ in "house", / / / in "decorations", / $\mathrm{y} /$ in "looking" or "opening", /r/ in "Harry" and /w/ in "winter" or "white", which were considered suitable to assess the children's strengths and weaknesses. Secondly, the length of the texts was similar, so that they were brief enough to be manageable by the children. Finally, while the word overlap between both passages was conspicuous (see Table 2 words in bold), the post-test also contained new lexical items to check for any possible transfer effects.

Table 2: Pre and post-test reading passages

\section{Pre-test Reading Passage}

It's Christmas Eve. It's snowy. Harry the mouse lives on a farm in England. He lives at the bottom of a wood pile.

The farmer has a big ginger cat. The cat's very clever. It eats mice. Harry doesn't like the cat.

\section{Post-test Reading Passage}

She gives Harry a cage. Harry the mouse has a very happy Christmas. He sees the big ginger cat but he isn't scared. "The cat can't eat me now," he says.

Harry eats nuts for his Christmas dinner."

The individual post-test oral interview was held in order to determine whether any pronunciation gains from the RR training sessions might carry over into the children's oral production. The interview consisted of sixquestionson the story content (eg. Who is Harry? What happens in the story? Where does Harry live? What is Harry the mouse afraid of? Which season are they in? What do you do at Christmas?), which could lead naturally to the production of the most frequent words and sounds used in the texts read in class during the training period. Questions demanding short, specific answers (1, 3, 4 and 5) were combined with those aiming at longer, more authentic responses ( 2 and 6$)$. While the former were mainly related to the pronunciation of sounds in words, the latter were intended to elicit stretches of genuine free speech from the children about their knowledge of the story and their personal experiences.

\subsection{Data analysis}

For the analysis of each learner's recorded performance in the pre and post-tests, a classification of pronunciation error types adapted from Monroy (2001) was used. This classification includes vowel and consonant errors as well as word stress errors (see Table 3). 
Two researchers, both highly experienced non-native teachers of English, one of whom had considerable expertise in teaching phonetics,coded each child's performance in the pre-test and reached a percentage of agreement for each category, ranging between $87 \%$ and $92 \%$.

Table 3 Pronunciation Error Types

\begin{tabular}{|c|c|c|}
\hline Category & Definition & Example \\
\hline VowelInsertion (VI) & Insertion of an inexistent vowel & (e)snowy \\
\hline VowelReduction (VR) & $\begin{array}{l}\text { Reduction of a diphthong to only } \\
\text { one vowel }\end{array}$ & $/ \mathrm{mIs} /$ instead of /mais/ in "mice" \\
\hline VowelSubstitution (VS) & $\begin{array}{l}\text { Substitution of a vowel for a dif- } \\
\text { ferent one }\end{array}$ & $\begin{array}{l}\text { /'kliva/ instead of /'kleva/ in } \\
\text { "clever" }\end{array}$ \\
\hline ConsonantInsertion (CI) & $\begin{array}{l}\text { Insertion of an inexistent conso- } \\
\text { nant }\end{array}$ & /gwvd/ instead of/wud/ in "Wood". \\
\hline $\begin{array}{l}\text { ConsonantSubstitution } \\
\text { (CS) }\end{array}$ & $\begin{array}{l}\text { Substitution of a consonant for a } \\
\text { different one }\end{array}$ & /livs/ instead of /livz/ in "lives". \\
\hline ConsonantOmission (CO) & $\begin{array}{l}\text { Omission of any consonant in the } \\
\text { word }\end{array}$ & /kəul/ instead of /Kəold/ in "cold" \\
\hline $\begin{array}{l}\text { ConsonantalGroupSimpli- } \\
\text { fication (CGS) }\end{array}$ & $\begin{array}{l}\text { Omission of a consonant within a } \\
\text { consonant cluster }\end{array}$ & /r:t/ instead of /r:ts/ in "eats". \\
\hline $\begin{array}{l}\text { Wrong pronunciation of a } \\
\text { Whole Word (WPWW) }\end{array}$ & $\begin{array}{l}\text { Incorrect pronunciation of a whole } \\
\text { word due to several inaccurate } \\
\text { phonemes }\end{array}$ & /'prle/ instead of /'pail/ in "pile" \\
\hline
\end{tabular}

After coding all the learners' errors across the different recordings, a frequency count was carried out for each error category. Given the limited sample size and the non-normal distribution of the data, non-parametric statistics were used with the data. Wilcoxon-signed rank tests were conducted to check for significant differences in the number of errors made by the children at Time 1 (the pre-test) and Time 2 (the three post-tests).

\section{Results}

The results obtained for the two research questions are reported below (see Table 4).

Research question 1 asked whether young EFL learners could improve their pronunciation through the assisted RR method. In order to answer this question, the number of errors made by the children when reading the same text at Time 1 (pre-test) and at Time 2 (posttest) was comparedThere was a reduction in the total number of errors from one stage $(\mathrm{n}=$ 136) to the next $(n=78)$, but this global result does not mean that the children were able to significantly decrease their errors in the eight categories considered. A Wilcoxon signedrank test showed that there was only a significant decrease in the reduction of vowels (VR) $(\mathrm{Z}=2.25 ; p=.02)$ and the substitution of consonants $(\mathrm{CS})(\mathrm{Z}=2.26 ; p=.02)$ and a marginally significant reduction in the insertion of vowels $(\mathrm{VI})(\mathrm{Z}=1.87 ; p=.06)$. 
The second research question was concerned with potential improvements in children's pronunciation both when reading new texts and in their own speech. This question was answered initially by counting the errors made by the children while reading the first passage in the pre-test and comparing them to those made while reading the new one (post-test 2). Globally considered, there was a slight reduction in the total number of errors between stages (136 and 108, respectively), although, once again, this reduction was not equally reflected in the eight error types. The Wilcoxon signed-rank test showed that, in line with the results in the previous question, the children were able to transfer to the reading of the new text their improvements in vowel reduction $(\mathrm{Z}=2,58 ; p=.01)$ and vowel insertion $(\mathrm{Z}=2,38 ; p=.01)$, but not those related to consonant substitutionIn contrast, they simplified significantly less their pronunciation of consonant groups $(\mathrm{Z}=2,33 ; p=.02)$.

In order to identify any pronunciation gains in the children's oral production, the number of errors in the pre-test was compared with those made by the children when answering the interview questions. There was a sharp decrease in the total number of errors between both stages (136 and 45, respectively), which, in contrast with the findings above, is clearly reflected in all the error types except for consonant omission, and consonant insertion. As shown by the Wilcoxon signed-rank test, the children were able to transfer to their oral rendition of the story a number of improvements related to vowel insertion $(Z=2,41 ; p=.01)$, vowel reduction $(Z=2,07 ; p=.03)$, vowel substitution $(Z=2,40 ; p=.01)$, consonant substitution $(\mathrm{Z}=2,55 ; p=.01)$, consonant group simplification $(\mathrm{Z}=1,98 ; p=.04)$ and, marginally, to word pronunciation $(\mathrm{Z}=1,84 ; p=.06)$.

Table 4: Changes in pronunciation errors before and after repeated reading.

\begin{tabular}{|c|c|c|c|c|c|c|c|c|c|c|c|c|}
\hline & \multirow{2}{*}{\multicolumn{3}{|c|}{$\begin{array}{l}\text { TIME } 1 . \\
\text { Pre-test }\end{array}$}} & \multicolumn{9}{|c|}{ TIME 2} \\
\hline & & & & \multicolumn{3}{|c|}{$\begin{array}{c}\text { Post-test 1: Same } \\
\text { text }\end{array}$} & \multicolumn{3}{|c|}{$\begin{array}{l}\text { Post-test 2: New } \\
\text { text }\end{array}$} & \multicolumn{3}{|c|}{$\begin{array}{c}\text { Post-test 3: Inter- } \\
\text { view }\end{array}$} \\
\hline & Total & Mean & SD & Total & Mean & $\mathrm{SD}$ & Total & Mean & $\mathrm{SD}$ & Total & Mean & SD \\
\hline Vowelinsertion & 24 & 3 & 1,60 & 11 & 1,38 & 1,40 & 4 & 0,5 & 0,74 & 1 & 0,12 & 0,35 \\
\hline Vowelreduction & 12 & 1,5 & 0,75 & 3 & 0,38 & 0,51 & 0 & 0 & 0 & 4 & 0,5 & 0,53 \\
\hline Vowelsubstitution & 13 & 1,63 & 1,18 & 7 & 0,88 & 1,12 & 14 & 1,75 & 1,16 & 0 & 0 & 0 \\
\hline Consonantinsertion & 15 & 1,87 & 0,83 & 7 & 0,88 & 1,12 & 5 & 0,62 & 0,91 & 9 & 1,12 & 0,99 \\
\hline Consonantsubstitution & 44 & 5,5 & 1,06 & 31 & 3,88 & 1,12 & 61 & 7,62 & 1,92 & 24 & 3 & 1,19 \\
\hline Consonantomission & 5 & 0,63 & 1,06 & 5 & 0,63 & 0,51 & 10 & 1,25 & 1,48 & 3 & 0,37 & 0,74 \\
\hline $\begin{array}{l}\text { Consonantgroupsimpli- } \\
\text { fication }\end{array}$ & 13 & 1,25 & 1,83 & 10 & 1,25 & 1,28 & 6 & 0,75 & 0,70 & 3 & 0,37 & 0,51 \\
\hline Word pronunciation & 10 & 1,25 & 1,83 & 4 & 0,50 & 0,75 & 8 & 1 & 1,77 & 1 & 0,12 & 0,35 \\
\hline
\end{tabular}




\section{Discussion}

The main purpose of the present study was to explore whether the use of Repeated Reading as a teaching method could encourage young EFL learners to improve their pronunciation of English both when reading aloud and when producing oral output. The data indicate that, as a group, the children significantly decreased their insertion and reduction of vowels when reading both known and unknown texts, although when it came to consonants, the benefits of RR only came to light in the reduction of errors involved in consonant substitution (when reading a familiar text) and simplification of consonant clusters (when reading a new text). On producing oral input, the children decreased the number of errors in all the categories so far mentioned, as well as in the substitution of vowels and the pronunciation of whole words. Consonant omission and insertion were the only two categories that did not seem to be affected by the RR method. In what follows, these findings will be interpreted in light of the relevant literature.

The erroneous insertion and reduction of vowels was significantly reduced after engaging in the RR sessions, a result that is in line with the findings reported by Monroy (2001). According to this author, anumber of researchers have claimed that Spanish speakers have a tendency to pronounce onsets in words beginning with $/ \mathrm{s} /+\mathrm{CC}(\mathrm{C}=\mathrm{Consonant})$ by inserting an initial vowel, generally /e/.Similarly, vowel reduction occurs when weak vowels disappear in the presence of other strong segments, for example when saying /pal/ instead of / pile/ (Monroy, 1980). However, in a study carried out with intermediate Spanish adult EFL learners Monroy (2001) found that vowel insertion was not consistent among the participants and that vowel reduction occurred on only a few occasions. The improvements on both these error types reflected in our data are in consonance with these earlier findings.

Regarding consonants, improvements in consonant substitution were found when the children were asked to read the familiar text and when they were interviewed, and a significant reduction in the number of cluster simplifications also came to light in the reading of the new text and in children's oral output. These findings contrast with those of Monroy (2001), however, whose older participants committed a greater number of errors in both categories. It is our contention that the children's frequent exposure to the printed word simultaneously with the reading aloud of the passages may have left a strong trace in their long-term memories, leading them to produce more accurate output both while reading and in the spoken interviews.

The frequencies of two error types, namely vowel substitution and word pronunciation,were found to decrease only in the children's free speech. This finding goes against theoretical assumptions which maintain that those sounds of the target language that are similar to those of the mother tongue are generally acquired with less effort than those which are different (Lado, 1957). Following this line of reasoning, youngerlearnersareheld to acquirefamiliar sounds more easily than dissimilar ones, unlike older learners (Major and Kim, 1999; Leather, 1999). Yet,the fact that most of our younger learners were able to lower the number of errors made,in spite of having to deal with words containing new, unfamiliar sounds, such as for example cage, afraid etc., suggests that age may not be a key factor in substitution processes. This is an area that calls for further research.

The erroneous pronunciation of whole words has not been generally been discussed as a category in the literature, as this usually involves multiple errors that affect theintelligibility 
of the word concerned. However, if we bear in mind that the children's inaccurate pronunciation of whole words improved only in the free speech test, we might speculate that this reduction of errors could be attributed to the nature of the language produced, which was mostly composed of words they knew well, having practicedthem through continuous repetition. It might also be explained by the lack of visual interference from grapho-phonemic associations, which are often the cause of pronunciation errors (LázaroIbarrola, 2011). Consequently, it is not surprising that the children accurately pronounced a high proportion of the words they produced in the oral interview.

The improvements discussed above are in close correspondence with other studies of RR that have reported students' gains in accuracy and fluency, two abilities that are highly related to pronunciation (Taguchi, Takayasu and Gorsuch, 2004; Wang and Kuo, 2011; Lázaro, 2011; Bouguebs, 2005). Wang and Kuo (2011) in particular, found that the RR method was an extremely useful technique for improving the number of correct words per minuteproduced by learners. Although the figures in the present study are not as high as those reported by Wang and Kuo, there is an undeniable connection between both studies, since WCPM measures the number of correctlyproduced words, i.e., accuratelypronounced sounds. Likewise, our findings as regards the children's oral production support results reported by Lázaro (2011) who found that "the scores that students obtained were sometimes lower (..), sometimes similar (..) and sometimes higher (...) than the ones they obtained in R2" (Lázaro, 2011:57), which is similarly reflected in the results reported above.

\section{Pedagogical implications and suggestions for future research}

Several implications for pronunciation teaching can be drawn from the results discussed above. Firstly, RR, as the present study has shownwould seem to be a suitable method to help children improve their English pronunciation skills. Teachers of younger learners, therefore, might consider the possibility of using this technique in their classes. Secondly, the implementation of additional teaching practices, such as, for example, simple phonetic transcription or raising learners'awareness of their own recordings might encourage children, in combination with RR, to enhance their pronunciation of the foreign language. Finally, we suggest that RR could be included in the repertoire of techniques that trainees are provided with during their initial teacher education studies. Future teachers could be asked, for example, to engage in peer appraisal while reading aloud, an activity that has been shown to help adult learners improve their pronunciation of words as well as their segmentation skills of phrase and sentence structures through repeated cycles of oral reading and listening to others read (Tost, 2013).

Despite the benefits involved in the use of RR, there are some limitations in the present study that should be borne in mind for future research. One of these limitations concerns the need to combine RR with the explicit teaching of phonemes, so that children might become aware of the variety of English sounds and of the difficulties involved in their pronunciation. The lack of suchexplicit teaching is one of the reasons that might be adduced to explain why the improvementsin the children's pronunciation here were only moderate. Similarly,since no attention was paid to supra-segmental issues, thiscould also be addressed 
in future studies, and with a wider range of children whose motivation was not as high as the learners in the present study. Finally, the design of the study did not allow us to claim with absolute certainty that the children were able to transfer their pronunciation gains from reading to genuine speech, as their oral production was too dependent on the story read in class. Further research could focus on the relationship between RR and the development of learners' oral skills in communicative situations.

\section{REFERENCES}

Blevins, W. and Lynch, J.(2000). Building Fluency: Lessons and Strategies for Reading Success. Scholastic Professional Book, Wiley Blevins.

Bouygues, R. (2005). The Effect of Repeated Reading on Reading Fluency: The Case of Second Year University EFL students at the English Department, ENS, Constantine, 2005. Mentouri University, Constantine (Algeria). MA thesis.

Chen, Y. and Chang, S. (2008). A Trial Study on using Readers Theatre with EFL Junior High Students. Paper presented at the 25th International Conference of English Teaching and Learning 2008 Taiwan.

Dowhower, S.L. (1987).Effects of Repeated Reading on Second Grade Transitional Readers' Fluency and Comprehension. Reading Research Quarterly, 22(4), 389-406.

Dwyer, M.A. (1983). Some Strategies for Improving Reading Efficiency. Forum, 12, 3:5-10.

Fraser, H. (1999). ESL Pronunciation Teaching: Could it be more effective? Australian Language Matters Journal, 7, 4: 7-8.

Gabrielatos, C. (2002). Reading Loud and Clear: Reading Aloud in ELT. ERIC Document Number ED477572.

Gibson, S. (2008). Reading Aloud: A Useful Learning Tool? ELT Journal, 62: 29-36.

Hulme C, Roodenrys S. (1995). Verbal Working Memory Development and its Disorders.Journal of Child Psychology and Psychiatry. 36, pp. 373-398.

Kendrick, H. (1997). Keep Them Talking! A Project for Improving Students' L2 Pronunciation. System, 25, 4: 545-560.

Lado, R. (1957). Linguistics Across Cultures.Michigan: University of Michigan Press.

LázaroIbarrola, A. (2011). Imitating English Oral Texts: A useful Tool to Learn English Pronunciation? Porta Linguarum, 16: 49-63.

Leather, J.H. (1999).Second-language Speech Research: An Introduction. Oxford: Blackwell.

Lloyd, S. and Wernham, S. (1994) The Phonics Handbook. Essex: UK Jolly Learning Ltd.

MacDonald, D., Yule, G. and Powers, M. (1994). "Attempts to Improve English L2 Pronunciation: The Variable Effects of Different Types of Instruction”.Language Learning, 44, 1: 75-100.

Major, R.C. and Kim, E. (eds.)(1999).The Similarity Differential Rate Hypothesis.Oxford: Blackwell.

Monroy, R. (2001). Profiling the Phonological Processes Shaping the Fossilised IL of Adult Spanish Learners of English As Foreign Language. Some Theoretical Implications, International Journal of English Studies, 1: 157-217.

Robertson, P. (2003). Teaching English Pronunciation Skills to the Asian Learner.A Cultural Complexity or Subsumed Piece of Cake? Asian EFL Journal, 5, 2: 1-26.

Superfine, W. (2009). The Christmas Mouse. London: Richmond Publishing.

Taguchi, E., Takayasu-Maass and Gorsuch, G. (2004).Developing Reading Fluency in EFL: How Assisted Repeated Reading and Extensive Reading Affect Fluency Development. Reading in a Foreign Language, 16: 1-19. 
Tost, G. (2013). Bettering Pronunciation Through Reading Aloud and Peer Appraisal. Bellaterra Journal of Teaching and Learning Language and Literature, 6, 35-55.

Wallace, C. (1992). Reading. Oxford: Oxford University Press.

Wang, Y. and Kuo, T. (2011). "A Study of How Repeated Reading Affects English Recitation Fluency in College Students". Chinese Journal of Applied Linguistics, 34, 2: 18-33.

Yule, G. and MacDonald, D. (1995).The Different Effects of Pronunciation Teaching. IRAL- International Review of AppliedLinguistics 33, 4: 345-50. 